\title{
Cuffitis: is an endoscopic approach possible?
}

\section{(ㄷ)(1) $(9)$}

Authors
Mélanie Serrero, Aurélia Santoni, Jean-Charles Grimaud, Ariadne Desjeux, Jean-Michel Gonzalez, Marc Barthet

Institution

Hôpital Nord, Marseille, France

submitted 1.11.2018

accepted after revision 9.7.2019

Bibliography

DOI https://doi.org/10.1055/a-0996-7975 |

Endoscopy International Open 2020; 08: E544-E547

(c) Georg Thieme Verlag KG Stuttgart · New York

eISSN 2196-9736

Corresponding author

Mélanie Serrero, Hôpital Nord, Marseille, France

Fax: +33-4-91961311

melanie.serrero@free.fr

\section{ABSTRACT}

Background Restorative proctocolectomy with ileal pouch-anal anastomosis (IPAA) is the reference surgical treatment for patients with ulcerative colitis (UC) refractory to medical treatment. One of the complications is leaving a strip of rectal mucosa which can be a cause of persistent inflammation or cuffitis. The objective of our study is to present an endoscopic approach for the treatment of cuffitis.

Methods This retrospective study included three patients who suffered from cuffitis after a proctocolectomy with IPAA for UC refractory to medical treatment. An endoscopic resection of the cuffitis was performed by the same operator. Two different techniques were used: hybrid endoscopic submucosal dissection (ESD) for one patient and mucosectomy with cap and resection for the two others.

Results The endoscopic treatment was performed successfully in all three patients. The only complication observed was rectal bleeding which did not require endoscopic revision. The three patients are now asymptomatic. Conclusion Endoscopic treatment of cuffitis appears to be an interesting approach with few complications in the short term and good clinical efficacy.

\section{Introduction}

Restorative proctocolectomy (RP) with ileal pouch-anal anastomosis (IPAA) is the reference surgical treatment for patients with ulcerative colitis (UC) refractory to medical treatment [1, 2]. Two types of anastomosis can be performed: hand-sewn anastomosis with mucosectomy of the anal transition zone, or mechanical anastomosis using the stapling technique. The latter may leave in place a strip of rectal mucosa [3], the maximum length of which must not exceed $2 \mathrm{~cm}$ between the dentate line and the anastomosis [4]. One of the complications is chronic inflammation of this rectal cuff, known as cuffitis. Although less common than pouchitis, it is nevertheless a real condition and can cause debilitating symptoms such as rectal bleeding, and may also lead to a risk of dysplasia or cancer [5].

Few studies have been published on the treatment of cuffitis and none to date have focused on an endoscopic treatment.

The objective of our study was to present a new treatment approach for cuffitis, consisting of endoscopic resection of the rectal cuff responsible for the symptoms, with the aim of improving the quality of life of the patient.

\section{Material and methods}

\section{Patients}

This retrospective study included three patients with a past history of UC that was resistant to treatment and which had required a RP with a mechanical IPAA.

In the follow-up period, all three patients presented with cuffitis that was confirmed endoscopically. The treatment consisted of endoscopic resection in the gastroenterology department of the Academic hospital Nord in Marseille between March 2017 and August 2018.

\section{Method}

The endoscopic procedures were carried out under general anesthesia by the same operator and required a short period of hospitalization. 
The first patient, a 59-year-old woman, presented with diarrhea and rectal bleeding 17 years after her RP. Endoscopy confirmed the diagnosis of cuffitis. The biopsies performed were compatible with a nonspecific subacute colitis, itself compatible with non-active UC. Despite a combined treatment with adalimumab and vedolizumab, maintained for 5 months, the patient did not present any clinical improvement, and there was a persistence of 6 to 7 bloody stools per day. This was the motivation for the endoscopic treatment. At the level of the anastomosis, the diagnostic rectoscopy revealed a sessile polyp with an adenomatous stalk measuring $25 \mathrm{~mm}$.

A gastroscope (Pentax, Tokyo, Japan) with a large operating channel $(3.8 \mathrm{~mm})$ was used for the procedure. The inflamed rectal cuff was resected using a hybrid technique, with submucosal dissection using the DualKnife (Olympus America, Center Valley, PA, United States) in the first stage, followed by resection of the ring around the pre-established groove in the second stage.

The second patient, a 26-year-old man, presented with pancolic UC since 2009 and underwent a RP with IPAA in 2016. The first surgical stage consisted of a subtotal colectomy with ileosigmoidostomy, followed 3 months later by a total proctectomy with mechanical IPAA initially protected by an ileostomy.

One year after surgery, the patient complained of diarrhea, with approximately 25 stools/day, including 7 at night, with bloody mucous and no clear response to either anti-motility agents or antibiotics (ciprofloxacin and metronidazole) initiated for possible pouchitis. The endoscopy performed concluded that there was probable cuffitis with the presence of a strip measuring $1-2 \mathrm{~cm}$ of congestive rectal mucosa in the supraanal area that bled in contact with the endoscope. The biopsies performed were compatible with the lesions of active UC. It was thus decided to adopt an endoscopic approach.

The third patient, a 29-year-old woman, underwent a RP at the end of 2017 for severe acute colitis in a context of UC. The initial surgical stage consisted of a subtotal colectomy with ileocolostomy, followed by a second stage with a proctectomy and creation of a robot-assisted mechanical IPAA, complicated by volvulus requiring repeat surgery on day 6 .

In the follow-up period to this surgery, the patient presented with severe rectal bleeding. The endoscope revealed the presence of a transitional mucosal zone measuring $1 \mathrm{~cm}$. This zone was inflammatory, hemorrhagic and erosive between the dentate line and the top of the anal canal. A treatment with antibiotic (metronidazole) had not been effective, motivating the endoscopic treatment.

For these two last patients, the resection was carried out by mucosectomy with the Duette system (Cook Medical, Bloomington, IN, United States) and a gastroscope (Pentax, Tokyo, Japan) with a large operating channel $(3.8 \mathrm{~mm})$ (cf. > Fig.1, - Fig. 2, - Video 1).

All patients received clinical monitoring in the hospital for at least 24 hours. All immediate and later complications were noted.

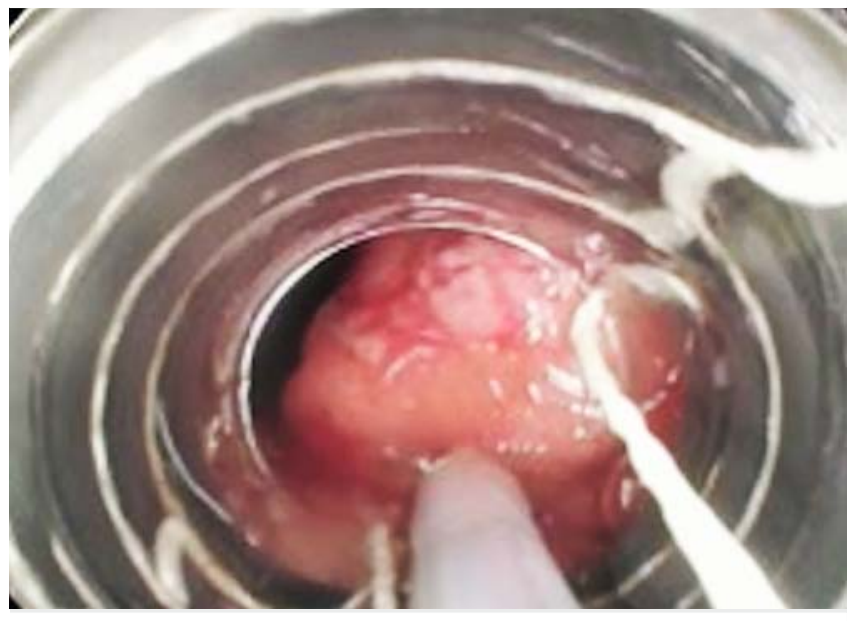

- Fig. 1 Mucosectomy with the Duette system.

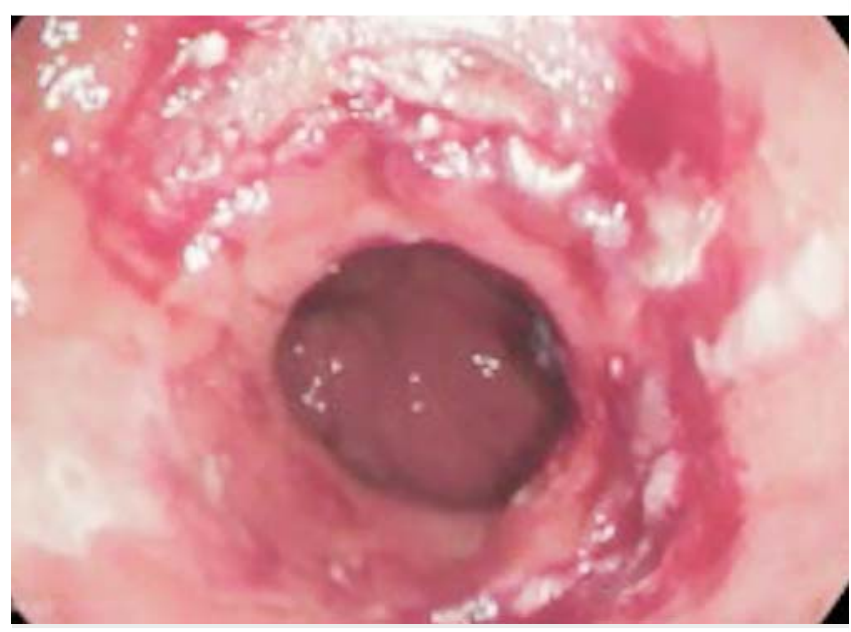

Fig. 2 Result after resection.

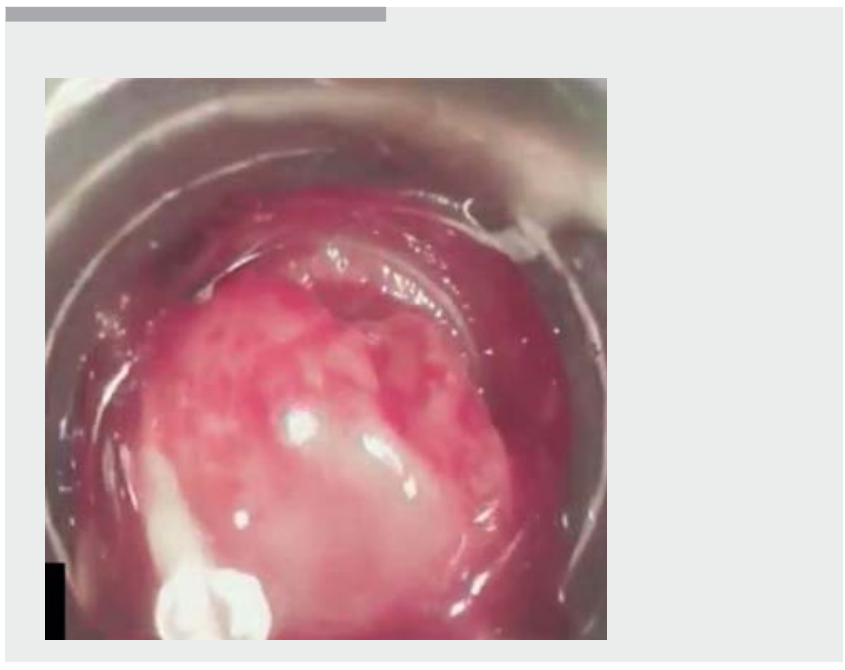

Video 1 Endoscopic treatment (cap and resection) of cuffitis for patients 2 and 3 in this study. 
- Table 1 Results of endoscopic treatment of cuffitis in the three patients in this study.

\begin{tabular}{|l|l|l|l|l|}
\hline $\begin{array}{l}\text { Pa- } \\
\text { tient }\end{array}$ & $\begin{array}{l}\text { Delay of on- } \\
\text { set of cuffitis } \\
\text { after IPAA }\end{array}$ & $\begin{array}{l}\text { Endoscopic } \\
\text { procedure }\end{array}$ & $\begin{array}{l}\text { Postopera- } \\
\text { tive course }\end{array}$ & $\begin{array}{l}\text { Effi- } \\
\text { cacy }\end{array}$ \\
\hline 1 & 17 years & Hybrid ESD & $\begin{array}{l}\text { Severe bleed- } \\
\text { ing }\end{array}$ & $\begin{array}{l}\text { Com- } \\
\text { plete }\end{array}$ \\
\hline 2 & 1 year & $\begin{array}{l}\text { Cap and } \\
\text { resection }\end{array}$ & $\begin{array}{l}\text { Slight bleed- } \\
\text { ing }\end{array}$ & $\begin{array}{l}\text { Com- } \\
\text { plete }\end{array}$ \\
\hline 3 & 5 months & $\begin{array}{l}\text { Cap and } \\
\text { resection }\end{array}$ & $\begin{array}{l}\text { Slight bleed- } \\
\text { ing }\end{array}$ & $\begin{array}{l}\text { Com- } \\
\text { plete }\end{array}$ \\
\hline
\end{tabular}

ESD, endoscopic submucosal dissection; IPAA, ileal pouch-anal anastomosis.

\section{Results}

The endoscopic treatment of cuffitis was performed successfully in all three patients (cf. > Table 1 ).

For the first patient, the treatment stage consisted of a submucosal dissection with the DualKnife (Olympus America) (the submucosa was very fibrous and hemorrhagic). Given the significant fibrosis, the dissection led to part of the mesorectum. It was then decided to complete the procedure with a hybrid technique involving resection of the ring of the polyp around the pre-established groove. The pathological analysis concluded that it was a hyperplastic polyp with a fleshy bud and no dysplastic modifications.

On postoperative day 10 , the patient presented with rectal bleeding without hemodynamic instability and did not require a packed cell transfusion. Treatment consisted of simple monitoring during hospitalization and she was discharged 72 hours later. No hemostatic agents were required.

One month after the resection, the patient's transit had normalized and she presented only slight rectal bleeding. The treatment with vedolizumab was thus stopped. The adalimumab had to be reintroduced for the treatment of her spondylitis. At present (1 year later), the patient has no symptoms.

For the second patient, the initial diagnostic approach revealed the presence of approximately $1 \mathrm{~cm}$ of rectal mucosa upstream of the anal canal. A mucosectomy was then performed on 4/5 of the circumference under the anastomosis and above the pectinate line using 10 elastic bands delivered by the Duette system (Cook Medical) using a cap and resection technique. The pathological analysis concluded that there was the presence of pseudo-polypoid inflammatory colic mucosa, with cytological modifications that were dystrophic but not dysplastic.

On day 1 following the procedure, the patient presented with occasional episodes of anal bleeding. There was no need for a transfusion and there was no hemodynamic instability. No hemostatic agents were required, and the treatment consisted of simple monitoring during a 5-day hospitalization period.

The patient did not present any further rectal bleeding in the following 6 months, but does have iron deficiency anemia requiring repeated intravenous injections.
For the third patient, a circular mucosectomy was performed with the Duette system (Cook Medical) using six elastic bands after detachment with an adrenaline-saline solution. Perioperative controls revealed circular resection over $1 \mathrm{~cm}$. The pathological analysis was compatible with lesions of UC without dysplasia.

Slight bleeding occurred in the immediate postoperative period. As a result, the patient was discharged on the day after the procedure. One month later, the patient has not experienced further symptoms or rectal bleeding.

\section{Discussion}

These three cases show that endoscopic resection of cuffitis is a good treatment alternative. The mucosectomy is a simple procedure, easily accessible to all endoscopists. The hospitalization periods required are also short. Moreover, the technique appears to present a certain amount of clinical efficacy, and has low morbidity, given the absence of serious complications reported even though studies with a larger number of patients are needed to confirm these data. Finally, it should be stressed that the only undesirable effect observed (early anal bleeding) did not require endoscopic revision.

Very few clinical studies have been published on cuffitis. The frequency of symptomatic cuffitis after RP and IPAA is nevertheless non-negligible [6, 7] and always requires treatment [7]. The question is thus: which treatment should be favored for this pathology today?

There is currently no published consensus with regard to the treatment of cuffitis following RP and IPAA. The recommendations of the ECCO [8] refer only to the non-controlled open study by Shen et al. on local treatment of cuffitis using mesalazine suppositories [6]. Their results revealed good clinical, endoscopic, and histological efficacy, but only 14 patients were included in that study. It is nevertheless legitimate to question the real efficacy of this local treatment in a group of patients already resistant to all medical therapy.

It is also possible to envisage surgical treatment, even though very few studies have been published on this subject. Fazio and Tjandra [9] described a series of two cases treated surgically using the transanal approach for symptomatic cuffitis and high level dysplasia at the level of the strip of rectal mucosa. One of the two patients had to have a temporary ileostomy for relief, raising the question of the morbidity of these procedures.

Finally, there is the matter of systematic treatments whose efficacy appears illusory in these patients already resistant to all medical therapy. In addition, the benefit-risk balance does not seem favorable for these aggressive treatments in the case of simple local relapse.

In conclusion, endoscopic treatment of cuffitis appears to be an interesting and novel approach with few complications in the short term and good clinical efficacy. It also seems to be a good alternative therapy for patients with cuffitis who are resistant to medical treatments. 


\section{Competing interests}

The authors declare that they have no conflict of interest.

\section{References}

[1] Parks AG, Nicholls RJ. Proctocolectomy without ileostomy for ulcerative colitis. BMJ 1978; 2: 85-88

[2] Fazio VW, Ziv Y, Church JM et al. Ileal pouch-anal anastomoses complications and function in 1005 patients. Ann Surg 1995; 222: 120 127

[3] Lovegrove RE, Constantinides VA, Heriot AG et al. A comparison of hand-sewn versus stapled ileal pouch anal anastomosis (IPAA) following proctocolectomy: a meta-analysis of 4183 patients. Ann Surg 2006; 244: $18-26$

[4] Gomollón F, Dignass A, Annese V et al. 3rd European Evidence-based Consensus on the Diagnosis and Management of Crohn's Disease
2016: Part 1: Diagnosis and Medical Management. J Crohns Colitis 2017; 11: 3-25

[5] Egan L, D'Inca R, Jess T et al. Non-colorectal intestinal tract carcinomas in inflammatory bowel disease: results of the 3rd ECCO Pathogenesis Scientific Workshop (II). J Crohns Colitis 2014; 8: 19-30

[6] Shen B, Lashner BA, Bennett AE et al. Treatment of rectal cuff inflammation (cuffitis) in patients with ulcerative colitis following restorative proctocolectomy and ileal pouch-anal anastomosis. Am J Gastroenterol 2004; 99: 1527-1531

[7] Lavery IC, Sirimarco MT, Ziv Y et al. Anal canal inflammation after ileal pouch-anal anastomosis. The need for treatment. Dis Colon Rectum 1995; 38: $803-806$

[8] Magro F, Gionchetti P, Eliakim R et al. Third European Evidence-based Consensus on Diagnosis and Management of Ulcerative Colitis. Part 1: Definitions, Diagnosis, Extra-intestinal Manifestations, Pregnancy, Cancer Surveillance, Surgery, and Ileo-anal Pouch Disorders. J Crohns Colitis 2017; 11: 649-670

[9] Fazio VW, Tjandra JJ. Transanal mucosectomy. Ileal pouch advancement for anorectal dysplasia or inflammation after restorative proctocolectomy. Dis Colon Rectum 1994; 37: 1008-1011 